\title{
Femoroacetabular Impingement: A Guide to Diagnosis in Primary Care
}

Alec Rimmasch Jr.

Patricia K. Ravert

Brigham Young University - Provo, patricia-ravert@byu.edu

Follow this and additional works at: https://scholarsarchive.byu.edu/facpub

Part of the Other Nursing Commons

\section{Original Publication Citation}

Rimmasch, A. J. \& Ravert, P. (2013). Femoroacetabular impingement: A guide to diagnosis in primary care. The Journal for Nurse Practitioners. 9(9), 606-611.

\section{BYU ScholarsArchive Citation}

Rimmasch, Alec Jr. and Ravert, Patricia K., "Femoroacetabular Impingement: A Guide to Diagnosis in Primary Care" (2013). Faculty Publications. 5281.

https://scholarsarchive.byu.edu/facpub/5281

This Peer-Reviewed Article is brought to you for free and open access by BYU ScholarsArchive. It has been accepted for inclusion in Faculty Publications by an authorized administrator of BYU ScholarsArchive. For more information, please contact ellen_amatangelo@byu.edu. 


\title{
Femoroacetabular Impingement: A Guide to Diagnosis in Primary Care Alec Rimmasch, Jr., RN, FNP, and Patricia Ravert, PhD, CNE
}

\begin{abstract}
Femoroacetabular impingement (FAI) has been a diagnosis for approximately a decade in the medical field. Although FAI was once considered uncommon, it is now documented as 1 of the most common hip disorders. FAI is a variance or overgrowth within the femoral head neck space, acetabular ring, labrum, or cartilage. Patients with FAI frequently present in a general practice setting and endure months of pain and physical therapy before a correct diagnosis is ascertained. Understanding FAI and appropriate treatment and diagnostic procedures will facilitate early diagnosis in the primary care setting, providing the best chance for patient recovery.
\end{abstract}

Keywords: CAM impingement, FAI, femoroacetabular impingement, hip pain, labrum tear, Pincer impingement

(C) 2013 Elsevier, Inc. All rights reserved.

$\mathrm{F}$ emoroacetabular impingement (FAI), once considered uncommon, is now 1 of the most documented hip disorders and a possible cause of many other hip-related disorders, such as labral tears of the acetabulum, sacral-iliac joint dislocation, lumbar spine malalignment, and early onset osteoarthritis (OA). ${ }^{1,2}$ Patients with FAI frequently present in a general practice setting and endure months of pain and physical therapy before a correct diagnosis is ascertained. ${ }^{3}$ Therefore, basic knowledge of the condition, symptoms, treatment, and diagnostic procedures is vital to early FAI diagnosis and management in the primary care setting.

\section{DEFINITION}

FAI is described as a variance or overgrowth within the femoral head neck space, acetabular ring, labrum, or cartilage. ${ }^{4-7}$ Pain is the primary complaint that brings patients in for workup and treatment. Two types of FAI exist: CAM-type impingement (femoral head and neck resemble a camshaft) and Pincer lesions of the acetabulum. The CAM-type impingement (Figure 1), common in young male athletes, is an abnormality of the femoral head/neck area or a pistol grip formation of the femur in which the femoral head has overgrown into the neck, causing an atypical abutment against the acetabular labrum.
A Pincer lesion (Figure 2), most common among active middle-aged women, involves an overgrowth of the acetabulum, arising mostly from repeated contact of the acetabular labrum against the femoral head/neck junction, which extends the labrum out and more medial to the femur. Over time this contact causes labral damage, ossifies the acetabular rim, and deepens the acetabulum, which causes abnormal joint alignment. ${ }^{9}$ The CAM-type impingement and the Pincer impingement occur separately and may be completely unrelated to each another but have been frequently associated when labral damage occurs.

The family nurse practitioner (FNP) who is prepared with the right questions, performs correct maneuvers during the physical exam, and knows what diagnostic tests to order can be a great asset to the patient with an ongoing hip complaint. With accurate diagnosis the FNP can refer the patient to physical therapy for joint mobilization or to an orthopedic specialist for FAI repair. Diagnosis, early treatment, and management should be the prime focus of an FNP when dealing with FAI. The focus is on preventing complications of early onset $\mathrm{OA}$ and labral damage. ${ }^{4,10-13}$ Early treatment also plays a role in the patient's ability to regain full function of the hip after surgery. 
Figure 1. CAM-type Impingement

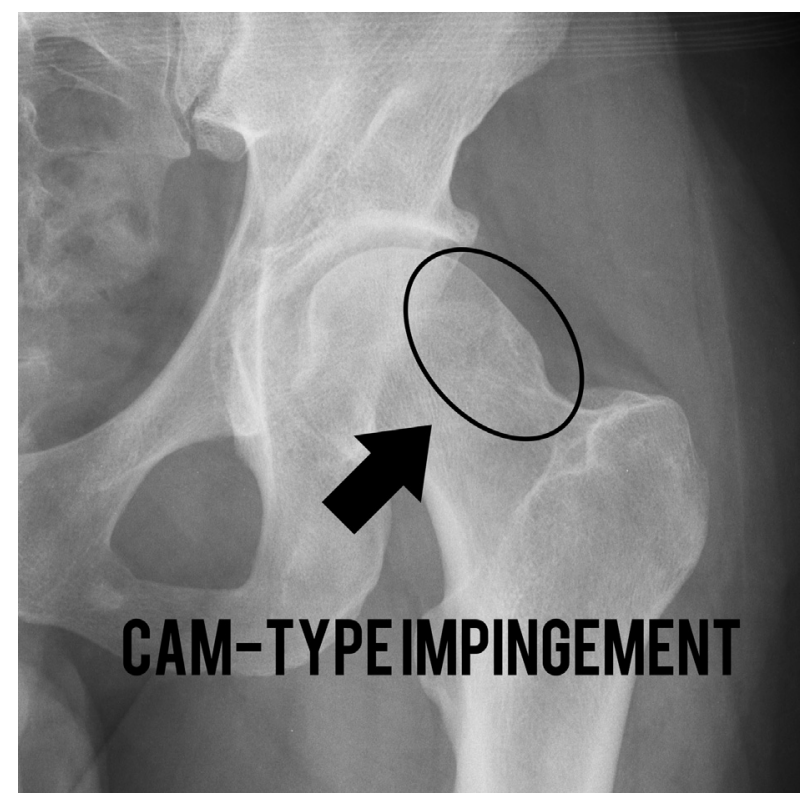

\section{SYMPTOMS}

Symptoms of FAI are insidious. Commonly, unilateral groin pain is present but not in conjunction with a known injury. The pain presents as an intermittent deep ache but slowly becomes more constant. The pain might be aggravated by physical activity, which can frequently lead to misdiagnoses. ${ }^{7}$ Pain in the groin with prolonged sitting in a computer-type chair is a common complaint. When ascertaining a patient history, a c-sign grip is a key indicator of FAI (Figure 3). The c-sign grip of the hip includes the medial groin and lateral buttock region. ${ }^{8}$ Clicking or catching of the hip is a common mechanical symptom and is more frequent when labral injury is present. Rest in a supine position, usually overnight, often relieves symptoms. Table 1 lists common FAI symptoms.

\section{ETIOLOGY}

Many childhood conditions, such as slipped capital femoral epiphysis, Legg-Calve-Perthes disease, developmental hip dysplasia, and mal-united fractures of the femoral neck, have been associated with FAI development later in adult life. ${ }^{4,14}$ FAI might have a genetic component as well, but the connection has not been well defined. ${ }^{4}$ High-impact physical sports, such as hockey, football, soccer, and ballet - all of which require internal rotation and increased compression of the hip - might cause a wear-and-tear-type osteophyte on the femoral head neck junction and lead to FAI. ${ }^{7}$

\section{EXAMINATION}

\section{Health History}

A complete hip history needs to be reviewed to rule out previous injury, condition, or familial history of any hip disorder that could be associated with the pain. Pain usually is the driving force for patients with FAI to seek medical care. History of pain should be determined by using OLDCART (Onset, Location, and Duration, Characteristics, Aggravating factors, Relieving factors, and Treatments attempted by the patient) or other appropriate pain assessment model. Treatments may include over-the-counter medications, physical therapy, narcotic medications, and or any other attempt to remedy the pain.

Many FAI patients describe pain with an insidious onset and intermittent to constant groin pain, with no injury to the groin. ${ }^{15}$ An FAI patient may also

Figure 2. Pincer Lesion Impingement

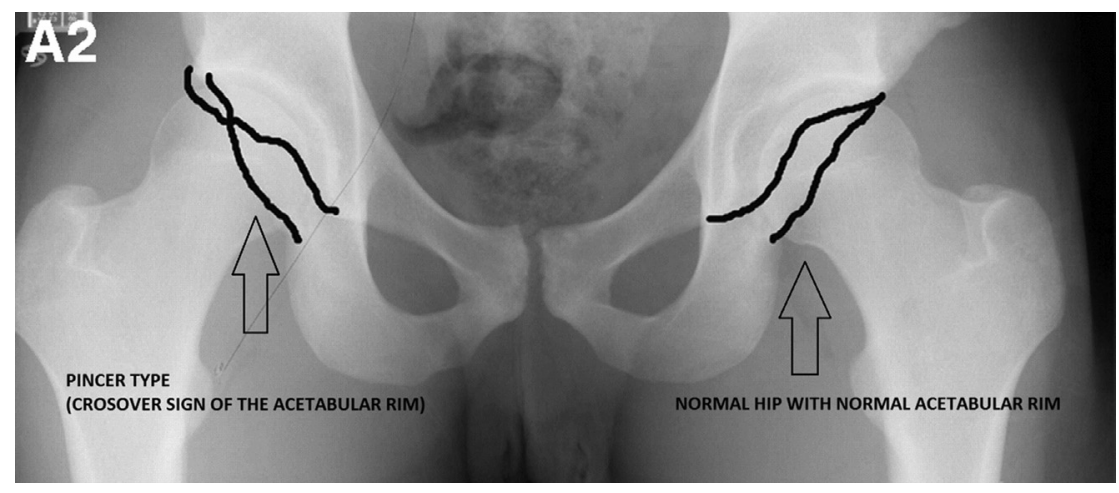


Figure 3. C-Sign Grip

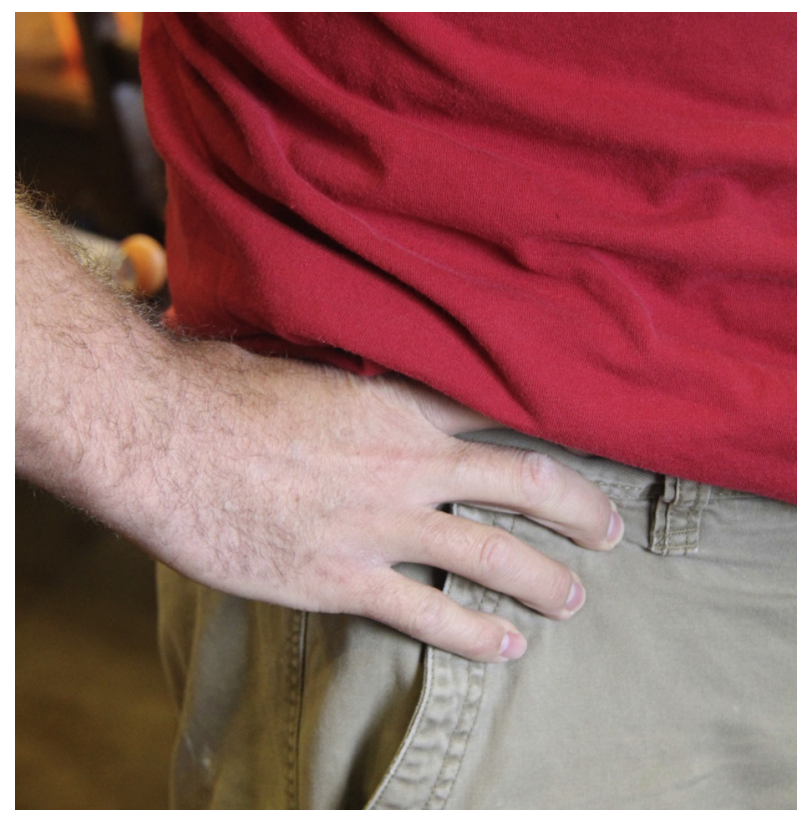

report a pinching or an overlapping sensation in the groin during a prolonged period of sitting in a chair, with dull, intermittent, or sustained pain in the hip that radiates to the buttock and lower back. ${ }^{7,16}$ FAI pain can be worse (though not always) after physical activity. ${ }^{17}$ Nonsteroidal anti-inflammatory drugs (NSAIDs) coupled with rest in a supine position, usually overnight, will generally relieve the aching pain of FAI.

\section{Physical Examination}

A thorough lower extremity physical exam of the hips bilaterally is important. The exam should include skin inspection for erythema and any blunt trauma to the hip region, palpation for edema, neurologic function of the lower extremities, strength of both hips, gait for irregular patterns of motion, and range

\section{Table 1. Common FAl Symptoms}

Insidious onset groin pain

Intermittent to constant pain

Pain exacerbated by prolonged sitting

Pinching or folding sensation near the inguinal canal

C-sign grip of hip

Clicking or catching of hip with movement

Relief of pain with supine rest, usually overnight, and

nonsteroidal anti-inflammatory drugs of motion (ROM), which can be limited in the affected hip. ${ }^{3,7,16}$ The diagnostic maneuvers FABER (Flexion, Abduction, and External Rotation) of the hip (Figure 4) and FADIR (Flexion, Adduction, Internal Rotation) of the hip (Figure 5) replicate motions that can cause pain and pinching in the groin, and they should be completed bilaterally., 3,4 FABER localizes pain, which can be at the hip, knee, or lower back. A positive finding of the FADIR maneuver suggests a probable diagnosis of FAI, and radiologic imaging should be ordered to confirm the diagnosis. Wang found that 21 of 21 patients with a positive FADIR examination had confirmed FAI. ${ }^{18}$

\section{Imaging}

$\mathrm{X}$-ray is the gold standard for confirming a diagnosis of FAI. A simple anterior-posterior and lateral x-ray of the lumbar spine and pelvis can uncover either condition: a pistol grip deformity, which is an irregularity of the femoral head neck (CAM-type impingement), or an early crossover of the anterior and posterior rims of the acetabulum (Pincer) (Figures 1 and 2). The $\mathrm{x}$-ray will also assist in the differential diagnosis for hip pain and rule out vertebral disc compression, OA, hip dysplasia, retroversion of the acetabulum, and osteonecrosis of the femoral head. ${ }^{5,6,9,16}$

If the patient complains of clicking or catching with movement, a magnetic resonance imaging arthrogram (MRA) of the hip should be ordered.' An MRA can reveal soft tissue abnormalities, such as labrum injury and masses near the joint. More importantly, an MRA can also provide information about the femoral head and its viability before surgery. ${ }^{6}$ Another option, but 1 rarely used due to high exposure to radiation, is 3-D computed topography, which provides 3-dimensional images and more fully determines the size and contour of a deformity on the femoral head or acetabulum preoperatively. ${ }^{7,19}$

\section{Differential Diagnoses}

Common conditions aside from FAI that cause hip pain include adductor strain, adult hip dysplasia, appendicitis, coxa saltans, endometriosis, greater trochanteric pain syndrome, iliopsoas tendonitis, inguinal hernia, labral tear, lumbar radiculopathy, lymphadenopathy, myofacial pain, osteitis pubis, and sacroiliac pain. ${ }^{5,20}$ Although FAI is 1 of the 


\section{Figure 4. FABER Maneuver}

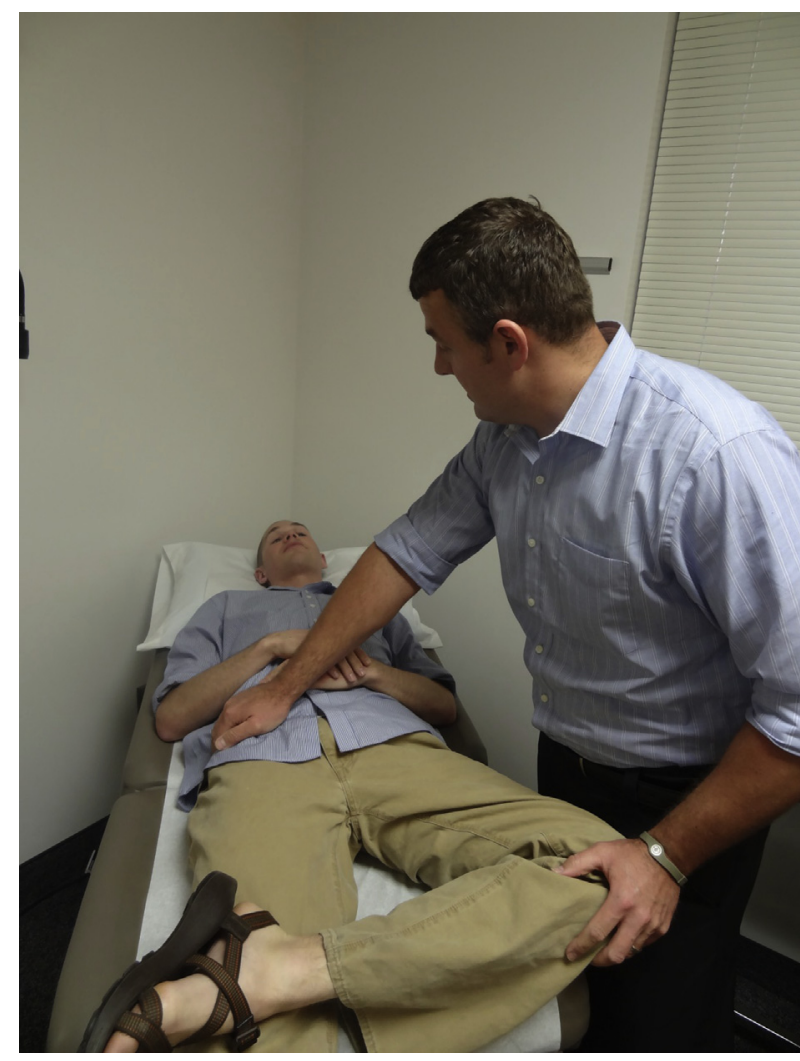

most underdiagnosed hip disorders, it is now recognized as 1 of the most important and urgent hip problems to treat. ${ }^{10}$

\section{DIAGNOSIS}

A careful review of the history of presenting symptoms, physical examination findings, and imaging will assist the FNP in determining the correct diagnosis. ${ }^{16}$ After an FAI diagnosis is made, a treatment plan should be developed to assist the patient in achieving the best outcome. The treatment plan should begin with conservative treatment, including rest from activities that aggravate the hip and physical therapy for ROM and strengthening the muscles around the hip.

\section{CONSERVATIVE TREATMENT}

FAI treatment should begin conservatively unless labral damage is known or degenerative $\mathrm{OA}$ is seen on imaging. Signs of labral damage or OA from FAI might indicate urgent need for surgical intervention to halt the progression of any further damage or permanent injury. $3,4,7,8,11,21$
Emara et $\mathrm{al}^{21}$ found that $72 \%$ of patients with mild FAI who completed conservative treatment received relief of pain and other associated symptoms. Conservative nonsurgical treatment includes physical therapy, pharmacological interventions, and complete rest from physical activity that perpetuates symptoms. ${ }^{3,7,8,21}$ Physical therapy should include core strengthening with active and passive ROM increases and bilateral leg strengthening. Patients should take NSAIDs to reduce pain. If conservative measures fail after 4-6 weeks of treatment, referral to an orthopedic surgeon well versed in FAI is recommended. . $^{7,21}$

\section{SURGICAL TREATMENT}

Surgical treatment of FAI can relieve pain and symptoms after postoperative pain subsides. ${ }^{8}$ Two modes of repairing FAI are open surgical dislocation of the hip with debridement and a less invasive arthroscopic approach with dislocation and surgical debridement. ${ }^{8}$ Long-term outcomes are not yet

\section{Figure 5. FADIR Maneuver}

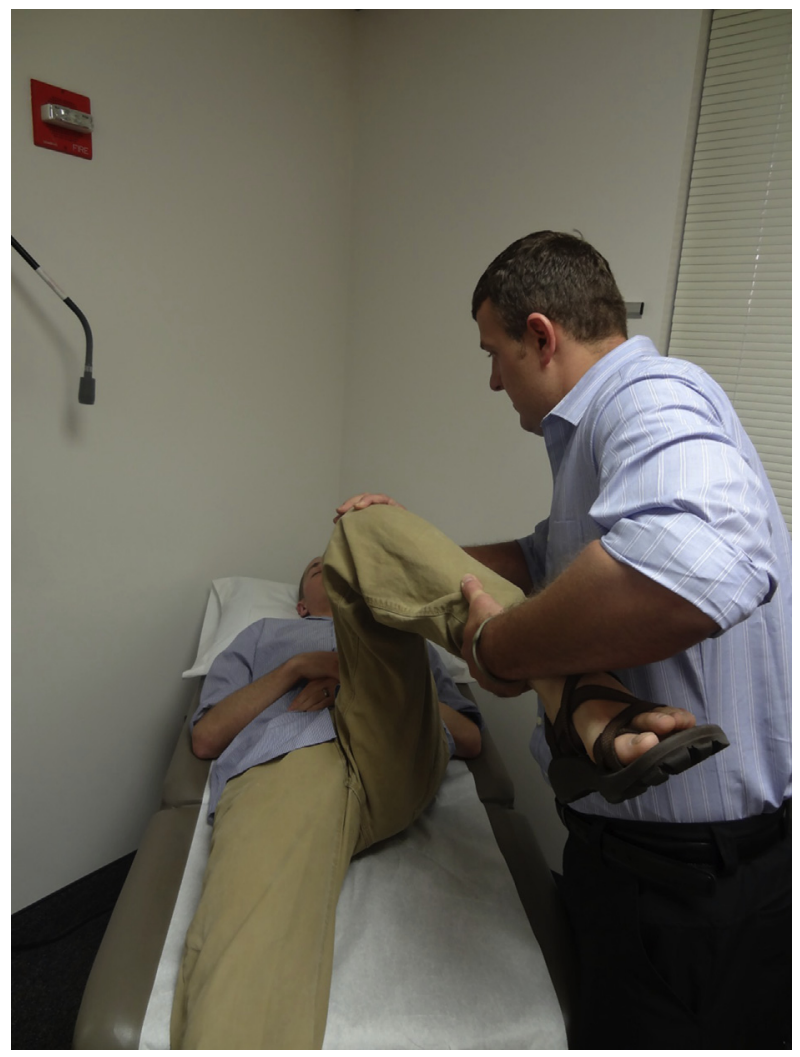


known for either procedure. Short term data at 6 to 24 months indicate good results, including relief of symptoms and pain. ${ }^{22}$

Ganz et al ${ }^{10}$ pioneered the open hip surgical repair of FAI. ${ }^{3}$ The advantages of having FAI repaired by the open hip method includes full visualization of the hip, ease of labral tear repair and Pincer impingements without compromising the posterior blood supply to the femoral head, and a low complication rate of $2 \%$ with no major problems. ${ }^{3,4,8}$ Disadvantages of the open repair include a longer recovery time, higher risk of infection, and possible trochanteric nonunion. ${ }^{8}$

Hip arthroscopy, which provides a minimally invasive approach to FAI repair, has recently shown great promise for faster recovery times and less postsurgical pain. ${ }^{4,7}$ Complication rates are less than $1.5 \%$ but include possible major complications of avascular necrosis of the femoral head, bleeding, cartilage injury, and neuropraxias. ${ }^{8,22}$ Both surgical approaches usually have similar postsurgical limitations. The restrictions include limited or nonweight-bearing decreased abduction with the hip flexed during recovery, which can be anywhere from 1 week with simple CAM repair or up to 6 weeks with labral involvement. These limitations are recommended to reduce the re-injury risk. ${ }^{7,8,21,23}$

\section{FOLLOW-UP CARE AND MANAGEMENT}

Follow-up care and postoperative rehabilitation after FAI repair studies have not been reported. Standards are based on individual orthopedic surgeon preferences. ${ }^{24}$ Generally, rehabilitation of a postsurgical hip includes physical therapy with joint mobilization and ROM for joint re-definition., ${ }^{4,24}$

On occasion patients who have only CAM-type impingements repaired via arthroscopic approach are able to bear weight with surgeon approval, whereas those who have open hip repair commonly have 6-8 weeks of $25 \%$ or less weight-bearing ability. Patients undergoing Pincer impingement repair via either method will have 6- 8 weeks of less than $25 \%$ weightbearing ability, with additional rehabilitation of the joint capsule. The key to full recovery is continued ROM and stretching after physical therapy. Although postsurgical follow up depends on the orthopedic surgeon preference, generally, patients are seen 1 week after surgery, then at 3 months and 1 year after surgery.

\section{CASE REVIEW}

History

A 29-year-old man with no previous history of hip injury entered the clinic with a constant, dull, aching pain and pressure in the right groin region. The pain radiated deep into the hip and low back and had progressively worsened over the past 6 months. He had been very active and participated in various sporting activities, but the pain had decreased his ability to take part. He had a decrease in agility and ability to turn sharply. He had tried to rest and apply ice to the groin but had not seen improvement. He had taken ibuprofen constantly for the past several weeks with minimal change in pain level. He had no family history of groin or hip problems.

\section{Physical Examination}

A physical exam revealed a healthy, active young adult with no obvious signs of injury or trauma. He was able jump, squat, and hop on the affected leg with minimal pain and compensation. Active and passive ROM of the affected hip were limited at full flexion. FADIR was extremely tight and reproduced significant pain. FABER was negative for pain.

The groin was soft to the touch, with no lumps or masses palpable. Some pain was reproduced with deep palpation of the hip joint itself. Upon initial review of the anterior-posterior and lateral $x$-ray, no abnormality was visualized, but, under further in-depth review by the radiologist, a small CAMtype lesion was identified and a crossover sign of the acetabulum bilaterally.

\section{Diagnosis}

FAI CAM-type and a Pincer lesion were identified, and because of the previous attempts at physical therapy, a referral was made immediately to an orthopedic surgeon. During the initial visit to the surgeon, the diagnosis was confirmed and a surgical intervention was discussed. The surgeon recommended the symptomatic hip be repaired via arthroscopic approach and set a surgical date. 


\section{Treatment}

The surgery was performed on a Friday with successful decompression of the CAM-type impingement and surgical touch-up of the acetabular labrum to lessen the Pincer lesion. The patient was released the same day, using crutches for ambulation. Physical therapy began the Monday after surgery, with ROM and stretching. Weight bearing progressed to 50\% by Wednesday. By the following Monday (10 days after surgery), he was walking without crutches and back to work. He continued physical therapy 2 days per week for 1 additional month. Later an MRA was completed of the left hip (nonoperative hip) because of new symptoms, clicking and catching, suggesting a torn labrum. The MRI arthrogram revealed a large anterior labral tear, which was repaired after full recovery of his right hip.

\section{CONCLUSION}

FAI is a common disorder of the hip. Early diagnosis and treatment of FAI might preserve hip integrity and prevent serious complications such as $\mathrm{OA}$ and the need for a total hip replacement at an early age. .,10,16 $^{-10}$ The key to recognizing FAI is to be familiar with most common presenting symptoms: deep groin pain with flexion and internal rotation, insidious onset of pain, relief of pain with extension and rest of the hip. Recognizing that the presenting symptoms may be a result of FAI and completing a thorough history and physical exam, including appropriate maneuvers FADIR and FABER, will help direct a diagnosis., 3 Ordering the appropriate $\mathrm{x}$-ray, or MRA studies if suspecting soft tissue damage, will help to confirm an accurate diagnosis. Diagnosing and treating FAI in a timely manner will ensure the best outcome and prevent further complications. ${ }^{4,9}$ Postoperative rehabilitation will aid a full recovery with the focus on a return to normal daily activities. ${ }^{25}$ JNP

\section{References}

1. Hack K, Di Primio G, Rakhra K, Beaulé P. Prevalence of cam-type femoroacetabular impingement morphology in asymptomatic volunteers. J Bone Joint Surg (Am). 2010;92(14):2436-2444.

2. Voos JE, Mauro CS, Kelly BT. Femoroacetabular impingement in the athlete: compensatory injury patterns. Oper Techniq Orthop. 2010;20(4):231-236.
3. Lever CJ, O'Hara J. Young adult hip disease: hip morphology and impingement. Curr Orthop. 2008;22(6):414-421.

4. Macfarlane RJ, Haddad FS. The diagnosis and management of femoroacetabular impingement. Ann R Coll Surg Engl. 2010;92(5):363-367.

5. Flannery O, Green C, Harmon D, Masterson E. Chronic painful conditions of the hip. Orthop Trauma. 2011;25(3):223-229.

6. Ejnisman L, Philippon MJ, Lertwanich P. Femoroacetabular impingement: the femoral side. Clin Sports Med. 2011;30(2):369-377.

7. Keogh MJ, Batt ME. A review of femoroacetabular impingement in athletes. Sports Med. 2008;38(10):863-878.

8. Samora JB, Ng VY, Ellis TJ. Femoroacetabular impingement: a common cause of hip pain in young adults. Clin J Sport Med. 2011;21(1):51-56.

9. Banerjee $P, M c L e a n$ CR. Femoroacetabular impingement: a review of diagnosis and management. Curr Rev Musculoskelet Med. 2011;4(1):23-32.

10. Ganz R, Parvizi J, Beck M, Leunig M, Nötzli H, Siebenrock KA. Femoroacetabular impingement: A cause for osteoarthritis of the hip. Clin Orthop Relat Res. 2003;(417):112-120.

11. Hart ES, Metkar US, Rebello GN, Grottkau BE. Femoroacetabular impingement in adolescents and young adults. Orthop Nurs. 2009;28(3):117-126.

12. Casartelli NC, Maffiuletti NA, Item-Glatthorn J, et al. Hip muscle weakness in patients with symptomatic femoroacetabular impingement. Osteoarthritis Cartilage. 2011;19(7):816-821.

13. Parvizi J, Leunig M, Ganz R. Femoroacetabular impingement. J Am Acad Orthop Surg. 2007;15(9):561-570.

14. Peters CL. Treatment of femoro-acetabular impingement with surgical dislocation and debridement in young adults. $J$ Bone Joint Surg $(A m)$. 2006;88A(8):1735-1741.

15. Blankenbaker DG, Tuite MJ. The painful hip: new concepts. Skeletal Radiol. 2006;35(6):352-370.

16. Kuhlman GS, Domb BG. Hip impingement: Identifying and treating a common cause of hip pain. Am Fam Physician. 2009;80(12):1429-1434.

17. Wisniewski SJ, Grogg B. Femoroacetabular impingement: an overlooked cause of hip pain. Am J Phys Med Rehabil. 2006;85(6):546-549.

18. Wang WG. Clinical diagnosis and arthroscopic treatment of acetabular labral tears. Orthop Surg. 2011;3(1):28-34.

19. Hossain M, Andrew JG. Current management of femoro-acetabular impingement. Curr Orthop. 2008;22(4):300-310.

20. Tibor LM, Sekiya JK. Differential diagnosis of pain around the hip joint. Arthroscopy. 2008;24(12):1407-1421.

21. Emara K, Samir W, Motasem EH, Ghafar KAE. Conservative treatment for mild femoroacetabular impingement. J Orthop Surg (Hong Kong). 2011;19(1):41-45.

22. Baldwin KD, Harrison RA, Namdari S, Nelson CL, Hosalkar HS. Outcomes of hip arthroscopy for treatment of femoroacetabular impingement: a systematic review. Curr Orthop Pract. 2009;20(6):669-673.

23. Reid GD, Reid CG, Widmer N, Munk PL. Femoroacetabular impingement syndrome: an underrecognized cause of hip pain and premature osteoarthritis? J Rheumatol. 2010;37(7):1395-1404.

24. Enseki KR, Martin RL, Draovitch P, Kelly BT, Philippon MJ, Schenker ML. The hip joint: arthroscopic procedures and postoperative rehabilitation. $J$ Orthop Sports Phys Ther. 2006;36(7):516-525.

25. Naal FD, Miozzari HH, Wyss TF, Nötzli HP. Surgical hip dislocation for the treatment of femoroacetabular impingement in high-level athletes. Am J Sports Med. 2011;39(3):544-550.

Alec Rimmasch Jr, RN, MS, FNP, is a critical care nurse at Intermountain Healthcare in Provo, UT. Patricia Ravert, PhD, $R N, C N E, A N E F, F A A N$, is dean and professor of the Brigham Young University College of Nursing in Provo, UT, and can be reached at patricia_ravert@byu.edu. In compliance with national ethical guidelines, the authors report no relationships with business or industry that would pose a conflict of interest.

$1555-4155 / 13 / \$$ see front matter

(c) 2013 Elsevier, Inc. All rights reserved.

http://dx.doi.org/10.1016/j. nurpra.2013.09.001 